\title{
MIDAS
}

Museus e estudos interdisciplinares

Dossier temático: "Políticas culturais e museus"

\section{Sofia Ponte - Transformar Arte Funcional em Objeto Museal}

\section{Miguel Ferrão}

\section{OpenEdition}

1 Journals

\section{Edição electrónica}

URL: https://journals.openedition.org/midas/2880

DOI: $10.4000 /$ midas.2880

ISSN: 2182-9543

\section{Editora:}

Alice Semedo, Paulo Simões Rodrigues, Pedro Casaleiro, Raquel Henriques da Silva, Ana Carvalho

Refêrencia eletrónica

Miguel Ferrão, «Sofia Ponte - Transformar Arte Funcional em Objeto Museal», MIDAS [Online], 13 | 2021, posto online no dia 15 dezembro 2021, consultado no dia 05 março 2022. URL: http:// journals.openedition.org/midas/2880 ; DOI: https://doi.org/10.4000/midas.2880

Este documento foi criado de forma automática no dia 5 março 2022.

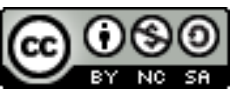

Midas is licensed under a Creative Commons Attribution-NonCommercial-ShareAlike 3.0 International License 


\title{
Sofia Ponte - Transformar Arte Funcional em Objeto Museal
}

\author{
Miguel Ferrão
}

\section{REFERÊNCIA}

Ponte, Sofia. 2020. Transformar Arte Funcional em Objeto Museal. Vol. 18. Coleção Estudos de Museus. Lisboa: Caleidoscópio e Direção-Geral do Património Cultural. 190 páginas, ISBN: 978-989-658-654-6.

1 A tarefa de formular uma integração entre a prática artística e as suas possibilidades de construção social, no que respeita à interligação entre ativação, autoria e comunidade, tem sido alvo de consecutivas tentativas de implementação e revisão, sobretudo no período que se seguiu à década de 1960. O primado da jogabilidade sobre a livre construção da vida no quotidiano, conduzida pelos seus próprios intervenientes empoderados, consubstanciada por Guy Debord e os Situacionistas; ou a tentativa de incluir todo o processo vital na produção estética, implicando a criatividade individual como capital transformador da estrutura social, proposta por Joseph Beuys, são exemplos paradigmáticos desta atitude, incorporando aquilo a que Ernesto de Sousa se viria a referir como uma arte necessária (Sousa 2011, 162).

2 A procura por uma função na arte, mediante a sua criação ou usufruto, desencadeou, desde então, múltiplos desenvolvimentos estéticos, estimulando a sua potencialidade emancipatória, visionária e interventiva. No mesmo sentido, uma abordagem interdisciplinar entre arte, design e práticas sociais, no âmbito da denominada viragem social da arte, tal como a definiu a historiadora Claire Bishop, em 2006, revelou-se igualmente determinante para este debate, recentrando-o sob o espectro da funcionalidade, i.e., a capacidade ou incapacidade de cumprir determinada tarefa, inerente a todos os atores nela envolvidos, humanos e não-humanos, individuais e coletivos. 
3 Em Transformar Arte Funcional em Objeto Museal, Sofia Ponte, doutorada em Arte e Design pela Faculdade de Belas-Artes da Universidade do Porto, explora precisamente este problema de caracterização, avaliação e interpretação num espetro particular da arte contemporânea, que define como Arte Funcional, fundamentando a sua análise num sólido conjunto de casos de estudo: The Homeless Vehicle (1988) de Krzysztof Wodiczko, paraSite (1998-) de Michael Rakowitz e Victory Gardens 2007+ (2007) de Amy Franceschini. Geracionalmente representativa, esta seleção incorpora a diversidade das estratégias estéticas implicadas nesta forma artística - da multifuncionalidade à portabilidade, da noção de serviço comunitário à aplicação modelar individualmente adaptada -, mantendo como central a relação entre objeto-processo e função-ação. Deste modo, a investigação de Ponte traça uma historiografia das principais transformações ocorridas a partir do questionamento do lugar da obra de arte na vida, mas também, de forma mais técnica e pedagógica, através da revisão dos lugares de performatividade cultural - como o museu e a exposição - e do papel dos seus agentes operativos, destacando-se, entre estes, o curador, o diretor de museu, o artista e o próprio visitante/utilizador/ destinatário das obras em questão.

4 Ponte opta pelo recurso ao termo Arte Funcional em detrimento de Estética Operacional uma alternativa viável, como nos indica - de modo a conduzir a sua investigação para as práticas artísticas que «produzem objetos de arte incidentes nos domínios conceptual, social e funcional» (p. 166) e que, pela sua aplicabilidade permanentemente reajustável, se revelam instáveis, quer na sua materialização, quer na sua musealização. Esta última dimensão, já de si continuamente colocada à prova pela pluralidade das práticas artísticas contemporâneas, incluindo as não-objetais, as duracionais e as sitespecific, incorpora o conflito entre a exposição, coleção e conservação destes objetos no âmbito da missão museológica, contextualizando-a como um enquadramento em permanente revisão. A obra de arte funcional vem assim contribuir para a redistribuição das funções do museu, ampliando o seu alcance para um espaço onde as relações de reciprocidade e de solidariedade possam afirmar um sentido de cidadania expandido (Arendt 1998).

5 Ao deslocar a obra de arte funcional para o espaço do museu e, em particular, para o âmbito da exposição como modelo de apresentação, pensamento e reativação, a discussão proposta por Ponte, faz-se, assim, através da genealogia destes objetos de arte conotados com diferentes noções de uso, associando o seu caráter efémero à Arte Pública e destacando a sua incidência sobre a localidade e especificidade, assim como a sua configuração colaborativa e participativa. Para Ponte, a ação disruptiva da esfera pública, que cada um destes projetos pressupõe, garante a efetividade precisamente mediante a sua implantação no quotidiano, partindo de uma configuração nãoestabilizada, sendo esse o paradoxo fundamental para o estabelecimento da sua funcionalidade enquanto ferramenta de intervenção social. São os próprios artistas representantes desta "variante da Arte Pública" (Ponte 2020, 42) que tendem a definir as suas práticas como uma manifestação de um trabalho que procura, literalmente, resultados, como observa, citada por Ponte, Amy Franceschini, autora de um dos projetos centrais para este estudo.

6 Alicerçada pelo debate acerca destas novas formas de relação, orientadas para uma função utilitária, tal como Jacques Rancière se refere às práticas estéticas que se «ocupam daquilo que fazem ao comum» (Rancière 2010), Transformar Arte Funcional em Objeto Museal discute as questões da participação, da representatividade e da identidade 
no âmbito da criação, da curadoria e do museu, garantindo, simultaneamente, lugar para a desconfiança sobre estes processos. Disso são exemplo as dúvidas levantadas por Lars Bang Larsen, em torno da sensação de efetividade no contexto social destas práticas, ou por Claire Bishop, relativamente à fusão da atividade artística com a praxis social como uma forma exponenciada de subordinação da audiência à vontade do artista, ambos convocados por Sofia Ponte.

7 Para Ponte, as obras de arte funcional impõem-se, deste modo, num plano de existência que não se limita ao domínio estético, colocando-se para lá da fruição formal ou simbólica, o que contradiz, desde logo, qualquer subjugação aos modelos expositivos centrados na separação entre objeto e espectador, entre ação e reação. Neste sentido, a autora reveste-se de um quadro metodológico para a análise dos seus casos de estudo que assenta na proposta "pós-conceptual" de Peter Osborne, um conceito composto por dimensões complementares caracterizadas pela materialidade revisível, pela abordagem conceptual que privilegia as consequências em detrimento dos pressupostos e pela mobilidade histórica dos seus componentes.

8 Paralelamente a esta tentativa de definição do conceito de funcional aplicado às obras de arte, Ponte explora as possibilidades, alterações e desvios conceptuais, formais e processuais decorrentes da "condução de determinados objetos para os museus» (p. 86), auscultando perspetivas contemporâneas sobre as denominações de objeto museal - aquele que se apresenta no espaço museológico - e de instituição cultural. Neste particular, a autora reconhece uma tendência, ainda longe da generalização, favorável à alteração dos sistemas de incorporação, coleção e utilização dos objetos de arte funcional no museu, por parte de diversos agentes ativos no contexto da arte contemporânea, incluindo Charles Esche, diretor do Van Abbemuseum, em Eindhoven (Países Baixos), como um dos principais promotores do desenvolvimento de um discurso curatorial que questiona e contraria criticamente a promoção aurática, autónoma e cristalizada do objeto artístico.

Para este fim, de acordo com Ponte, têm contribuído as abordagens curatoriais que interpretam a exposição como espaço de transformação de todas as instâncias envolvidas, concorrendo para o entendimento do estatuto do objeto artístico como objeto interrelacional; para a problematização da exposição como "canal de comunicação" (p. 112); e para a desmodernização do contexto museal como um todo. Esta mudança de paradigma identificada pela autora tem conduzido a "dinâmicas expositivas experimentais" (p. 113) capazes de gerar conhecimento novo, novas aprendizagens e relações entre obras e usufruidores, entre artistas e curadores e entre o museu, enquanto instituição, e a sua estrutura operacional, exigindo a reformulação do seu próprio funcionamento.

10 Ao recorrer a exemplos paradigmáticos desta problematização do museu, do objeto museal e da obra de arte funcional, incluindo as pioneiras apresentações públicas de The Homeless Vehicle, onde a visualização da obra na cidade, transportada por pessoas em condição de sem-abrigo, teve um impacto sociopolítico; as iterações transformativas de paraSite, cuja exposição foi profundamente alterada pelas contribuições pessoais dos seus utilizadores; ou a relevância da documentação secundária para a compreensibilidade do alcance comunitário de Victory Gardens 2007+; esta publicação consolida o estatuto multidisciplinar deste tipo de manifestação artística, dando conta dos desafios que impõe a sua transposição e consequente recontextualização, por parte da atividade curatorial. 
11 A investigação da autora aponta, assim, para uma credibilização artística destas práticas, ressalvando, contudo, a sua distinta relação com formas de consumo convencionais. A disponibilidade para a metamorfose que estes objetos obtêm em contexto museal reafirma, deste modo, a exploração do formato da exposição como um contínuo devir que, longe de estar esgotado, não só dá conta da existência desses mesmos objetos artísticos como ramifica pública e temporalmente os seus desígnios (O’Neill 2018, 148), ainda que à custa de consideráveis adaptações. A leitura de Ponte participa, deste modo, na demarcação da diferença entre função e funcionalidade no que respeita às práticas artísticas englobadas na denominada Estética da Participação Social. 0 trabalho desenvolvido acrescenta, consequentemente, valor empírico e teórico à desambiguação dos processos que definem a Arte Funcional, estimulando o debate em torno das suas motivações, produções e consequências.

\section{BIBLIOGRAFIA}

Arendt, Hannah. 1998. The Human Condition. 2. ed. Chicago: The University of Chicago Press.

Bishop, Claire. 2006. "The Social Turn: Collaboration and Its Discontents." Artforum International, vol. 44, n.․ 6 (Fev.): 178-183.

O'Neill, Paul. 2018."Exhibitions as Curatorial Readymade Forms of Escape." In What Museums Do: The Curatorial in Parallax, ed. Choi Jina e Helen Jungyeon Ku, 143-158. Seoul: National Museum of Modern Art.

Rancière, Jacques. 2010. O Espectador Emancipado. Traduzido por José Miranda Justo. Lisboa: Orfeu Negro.

Sousa, Ernesto de. 2011. "Oralidade, Futuro da Arte?" In Oralidade, Futuro da Arte? e Outros Textos, 1953-87, org. Isabel Alves. São Paulo: Escrituras Editora.

\section{AUTORES}

\section{MIGUEL FERRÃO}

Doutorando em Estudos Artísticos - Arte e Mediações, Faculdade de Ciências Sociais e Humanas da Universidade Nova de Lisboa, Portugal, miguelnogueiraferrao@gmail.com 